\title{
The Effect of Using STEAM Approach on Motivation Towards Learning Among High School Students in Jordan
}

\author{
Rana Waleed Al-Haj Bedar ${ }^{1}$ \& Muhannad Anwar Al-Shboul ${ }^{2}$ \\ ${ }^{1}$ Philadelphia National Schools, Amman, Jordan \\ ${ }^{2}$ Department of Curriculum and Instruction, School of Educational Sciences, The University of Jordan, Amman, \\ Jordan \\ Correspondence: Muhannad Anwar Al-Shboul, Professor of Educational Technology and e-Learning, Department \\ of Curriculum and Instruction, School of Educational Sciences, The University of Jordan, P. O. Box 13244, \\ Amman 11942, Jordan. E-mail: malshboul@ju.edu.jo
}

Received: April 8, 2020

Accepted: May 30, $2020 \quad$ Online Published: August 24, 2020

doi:10.5539/ies.v13n9p48

URL: https://doi.org/10.5539/ies.v13n9p48

\begin{abstract}
This study aimed at investigating the effect of applying integrated Science, Technology, Engineering, Art, and Mathematics (STEAM) approach on motivation among students of grade 10 in a private school in Amman. In this context the researchers used a quasi-experimental method. The sample of this study involved 32 high school students; the individuals of the study were intentionally chosen and distributed randomly into two groups: the control group consisted of 19 students who studied Geography in a conventional way, and the experimental group consisted of 13 students who studied the same content using STEAM approach. To achieve the study goals, the researchers developed an instrument to measure motivation towards learning geography that focused on the following constructs of motivation: Internal Motivation, Grade Motivation, Class Anxiety, Career Motivation, Self-Efficacy, and Teacher Obedience. After verifying its validity and reliability, the instrument was applied on the study sample. The results of the analysis of covariance (ANCOVA) showed no significant difference on motivation in all of its constructs except for (Class Anxiety) which was in favor of the experimental group. The study recommended providing teachers with enough and valuable training opportunities on how to activate STEAM approach to ensure meaningful learning for students and to increase their awareness to future careers including STEAM jobs.
\end{abstract}

Keyword: STEAM approach, conventional method, motivation towards learning, Jordan

\section{Introduction}

Societies worldwide are increasingly steered to be technology-dependent and people are becoming digital citizens. Computers, tablets, and smart phones are currently spread enormously in our world, which is becoming gradually more driven by technology (International Society for Technology in Education (ISTE), 2016). On the other hand teaching practices are thriving to grab continues attention of learners. Establishing environments that are motivation- fostering seems a challenging goal. The debate on ways of embedding technology in education is an everlasting argument. Dynamically, we are faced with new methods and tools that all aim to boost motivation and provide meaningful learning. One of these methods is the integrated Science, Technology, Engineering, Art, and Mathematics (STEM) approach that is shifted to become STEAM, with the "A" stands for Arts and Humanities. The origin of STEAM term was in 1990's by the National Science Foundation (NSF) in USA. In many educational reforms that take place today, STEM is considered as a supportive approach that emphasizes on the multidisciplinary approach to better prepare students for STEM occupations and to compete in the global economy (Thomasian, 2011). STEAM approach including Arts and Humanities (Geography, Civics, and History) has been grabbing attention for five years as a more recent phenomenon (Ghanbari, 2015). Simply it is the welling to combine science, technology, engineering and mathematics with arts and humanities in an integrated paradigm. There is no doubt that the teacher's role inside the classroom is transferring from being the responsible of designing learning experiences to a facilitator who helps students become responsible of their learning , through methods and practices that emphasize on problem solving and hypothesis testing (Gujjar \& Naoreen, 2009) in environment that enhances students levels of motivation as possible. Therefore, because of the importance of the motivation towards learning Geography and its expected impact on learning outcomes in 
general, this study investigated the effect of using STEAM approach on motivation towards learning among 10th basic grade students in Geography subject in the international curriculum in Jordanian private schools.

\subsection{Background}

Efficient learning is possible if motivation was present. In case of low motivation levels, the learning process would slow down, teaching and learning must happen in parallel. Educators and teachers need to consider students' desires, which will enhance student-centered learning. Conducting some learning activities, even those involving abstract style, in a meaningful contexts (authentic) to students, should have significant beneficial effects on their intrinsic motivation and learning (Cordova \& Lepper, 1996).

Two types of motivation were of interest in this study; intrinsic motivation and extrinsic motivation. These two differ in the goal behind action taken. Intrinsic motivations reflects the human's tendency to learn and understand and refers to doing something that is pleasant, while extrinsic motivation deals with external factor that controls behavior of human and refers to doing something that results from outer stimulus. These types are related to human needs discussed previously such as relatedness and exchange of respect. Students vary in their motivation levels as well as their orientations of motivation. Add on that the quality of experience gained and performance observed vary based on the type of motivation that drives the student (Deci \& Ryan, 2000).

There are several ways teachers do to motivate learners such as: Well organized and systematic presentation prepared by the teacher; Use of variety teaching methods (in this study STEAM and Conventional); Conductive learning environment including a classroom setting; the availability of teaching and learning resources; the relationship between students, teacher's personality, knowledge, skills, ideas, attitudes and perceptions (Ababio, 2013). Motivation's indicators that shows that a student is motivated in a task or topic may include: Focus in finishing the task; Doesn't easy give up and satisfied with his/her achievement; Interested in the various problems; Working independently; Quickly bored with routine tasks; Stick with his/her own ideas; Not easy to let go on what he/she they believes; Interested in finding and solving problems (Sardiman, 2014 as cited in Ningrum, Ruhimat, \& Wijayanto, 2017).

In the beginning of 2000's, there was a global agreement on role of ICT in school education. For the past 20 years, there had been a growing call to integrate ICT in learning to increase students' motivation towards learning, in a funny attractive way in a well-planned environment. It also helped in achieving students' mastery goals in different topics and enhanced collaboration and interaction. Simulation and virtual environments used in teaching-learning process showed increase in the excitement rates in learning content. So, use of technology [embedded in STEAM approach] is expected to help in engaging students more in learning process (Eboy, Rathakrishnan, Sharif, Singh, $\&$ Talin 2016).

\subsection{Previous Studies}

Chiang and Lee (2016) conducted a quasi-experimental study that aimed at examining the effect of Project Based Learning on motivation levels and problem-solving skills among students at two vocational high schools in Taiwan. Results showed that students of the experimental group at one of these schools significantly improved in motivation level as well as in problem-solving skills.

Rana, Mahmood, and Reid (2015) explored the cause effect relationship between students' motivation for learning, interest and academic performance in science among eighth grade students. Results showed that students in the experimental group scored significantly higher in the motivation scale that those who learned using conventional method. Moreover, the result of confirmed that student motivation for learning science has significant effect on academic performance. The study revealed significant positive relationships among different categories of motivation towards science learning and achievement. Gender and interest of students was found a significant source of variation in student performance. Additionally, the study affirmed that students' interest in science also has significant effect on their motivation towards learning science.

Han et al. (2014) conducted a study that aimed at identifying the influence of STEAM education program on creativity and interest levels in Science, for grade six students in (3) schools in Korea. They developed a STEAM education program that was taught as a closing part of units and themes. Results showed that students of experimental group, who studied using their STEAM program, had significantly improved their creativity and levels of interest in Science compared to those in control group.

Ji and Kong (2014) investigated the effect of a developed STEAM activity programs on scientific attitudes, self-efficacy, and motivations towards learning Science among sixth grade students in elementary school in Korea. His study included (19) students in the experimental group and (35) students in the control group. The results of this study showed that there was a significant positive influence of STEAM activities applied during Science 
classes on students' motivation towards learning and it changed their attitude towards Science in the experimental group.

Al-Kassab (2011) conducted a study that aimed at identifying the effect of using the reciprocal method in teaching, which included prediction and asking questions strategies, on the achievement and motivation towards learning among students of 10th grade in Geography at Irbid Governorate Schools. A study sample that included 133 students was divided randomly into two groups; experimental and control in a quasi- experimental design. The experimental group studied using the reciprocal method while the control group studied using conventional method of teaching. Results showed that motivation towards learning geography was enhanced and achievement test scores were better for the students of the experimental group.

Chen and Howard (2010) conducted a study that aimed at examining the effect of using simulation (Satellite data and images) on students' attitudes and learning towards Science and the influence of motivation on students' achievement in general. The study was held among (311) high school students in Taiwan. Results showed that students' of the experimental group, who accessed and interpreted Satellite images and data, had improved their attitudes and awareness towards Science and Science career significantly compared to the control group.

\subsection{Commentary on Previous Studies}

The researchers noticed through the review of previous studies a deprived focus on the measure of the effectiveness of STEAM approach on the level of motivation towards learning especially in geography. On the other hand, there was a focus on science (Ji and Kong, 2014), Mathematics, and Computer science subjects, with less emphasis on Humanities and Arts. Few studies like Al-Kassab (2011) focused on geography, which was also stressed in this study. In addition, the reviewed studies included mostly a case study style research (Han, Hong, Kim, and Ko (2014) rather than experimental or quasi-experimental research, which was endorsed in this study. All of the reviewed studies formed a rich database for the researchers to benefit from either in the design or the development of the study instruments. This study differs from the previous studies in that it will investigate the impact of STEAM approach on motivation towards learning among 10th grade students in Jordan through three decent grafted activities in Science, technology, Mathematics, engineering and Geography.

\subsection{Study Questions}

Based on the viewed literature the research question is: What is the effect of using STEAM approach on motivation towards learning geography at the level of $(\alpha=0.05)$ among 10th grade students in Jordan?

\section{Research Methodology}

\subsection{Participants of the Study}

The population of the study included the students aged (14-16) at the international sections (IGCSE) in the Jordanian private schools who were studying Geography subject. The sample of the study was intentionally selected from the international section in Philadelphia National School, and it included all the students of 10th basic grade in the international section with a total number of (32) students. The individuals of the sample were randomly distributed into two groups: control and experimental. The control group consisted of (19) students were taught using conventional method of teaching, while the experimental group that consisted of (13) student was taught using STEAM approach. Table 1 shows the distribution of the sample of the study.

Table 1. The distribution of the sample

\begin{tabular}{|c|c|c|}
\hline Group Name & Teaching Method & Number of Participants \\
\hline Experimental & STEAM & 13 \\
\hline Control & Conventional & 19 \\
\hline Total & & 32 \\
\hline
\end{tabular}

\subsection{Sampling Procedures}

\subsubsection{Sampling Method}

This study investigated the effect of STEAM approach on motivation towards learning geography among 10th grade students. The study followed the quasi-experimental method in which the sample was intentionally selected from a private school in Amman, where all settings, resources, data shows, laptops were available, however individuals of the sample were distributed randomly into two groups; experimental and control. 


\subsubsection{Measures and Covariates}

A scale was prepared to measure motivation towards learning geography among 10th grade students. The researchers benefited from the instruments of the previous studies (Brickman, Glynn, \& Taasoobshirazi, 2009; Armstrong, Brickman, Glynn, \& Taasoobshirazi, 2011). The scale included the following constructs: intrinsic motivation, self-efficacy, career motivation, grade motivation, teacher obedience, class anxiety. The scale items had Likert-type scale responses, distributed as: (5) Strongly Agree, (4) Agree, (3) Neutral, (2) Disagree, (1) Strongly Disagree. The total score was (80). The instrument was validated by number of experts in curriculum and instruction as well as educational technology and Computer science at the University of Jordan and Princess Sumaya University for Technology. According to interpretations from the academic referee panel, the researchers modified both instruments of study. The motivation towards learning scale originally consisted of (20) items. The researchers modified six items and removed four other items based on referee comments and the final version of the scale contained (16) items. The scoring on the motivation towards learning scale, which was Likert-type was set to $(1)=$ strongly disagree, $(2)=$ disagree, $(3)=$ normal, $(4)=$ agree, $(5)=$ strongly agree. The total mark of the scale was (80). An Inter-Rater reliability coefficient was calculated using the following equation: Inter-Rater reliability coefficient $=$ number of agreements/(number of agreements + number of disagreements); in other words, an agreement of $(80 \%)$ among experts (Miles \& Huberman, 1994). The Inter-Rater reliability coefficient for motivation towards learning scale was $(89 \%)$.

To ensure that the two study groups were equivalent in motivation towards learning prior to treatment; the instrument was applied on the experimental group and the control group as shown in Table 2 below.

Table 2. T-test (Independent Sample Test) results of the study sample prior to treatment in motivation

\begin{tabular}{|c|c|c|c|c|c|c|}
\hline Motivation Constructs & Group & $\mathrm{N}$ & Mean & Std. Deviation & $\mathrm{t}$-value at df of (31) & Sig. (2-tailed) \\
\hline \multirow{2}{*}{ internal_motivation_pre } & Experimental & 13 & 11.683 & 3.093 & \multirow{2}{*}{0.386} & \multirow{2}{*}{0.704} \\
\hline & Control & 19 & 11.321 & 2.029 & & \\
\hline \multirow{2}{*}{ grade_motivation_pre } & Experimental & 13 & 11.766 & 2.455 & \multirow{2}{*}{0.341} & \multirow{2}{*}{0.736} \\
\hline & Control & 19 & 11.469 & 2.342 & & \\
\hline \multirow{2}{*}{ class_anxiety_pre } & Experimental & 13 & 8.769 & 2.088 & \multirow{2}{*}{0.322} & \multirow{2}{*}{0.749} \\
\hline & Control & 19 & 8.465 & 3.098 & & \\
\hline \multirow{2}{*}{ career_motivation_pre } & Experimental & 13 & 7.150 & 1.625 & \multirow{2}{*}{0.057} & \multirow{2}{*}{0.955} \\
\hline & Control & 19 & 7.115 & 2.726 & & \\
\hline \multirow{2}{*}{ self_efficacy_pre } & Experimental & 13 & 7.455 & 1.330 & \multirow{2}{*}{1.198} & \multirow{2}{*}{0.240} \\
\hline & Control & 19 & 6.785 & 1.843 & & \\
\hline \multirow{2}{*}{ teacher_obedience_pre } & Experimental & 13 & 12.383 & 1.502 & \multirow{2}{*}{-0.463} & \multirow{2}{*}{0.647} \\
\hline & Control & 19 & 12.681 & 2.162 & & \\
\hline
\end{tabular}

As shown in Table 2 the $t$-value is not significant in all constructs of motivation towards learning since they are all above (0.05). This implies that both groups were equivalent in motivation towards learning prior to the treatment. A negative $t$-value is observed in the teacher obedience construct that indicates a reversal in the directionality of the effect, which has no bearing on the significance of the difference between the two groups of the study.

\subsection{Research Design}

Both groups were trained on the following geography skills: (1) Map Working; (2) Diagrams, Graphs, Tables and Illustrations Interpretation; (3) Photographic and Pictorial Material Analysis. The focus was on skills rather than the knowledge or content. The experimental group learned using STEAM approach while the control group learned using conventional method of teaching. The study was conducted in a four weeks period during the fall semester 2019/2020 as shown in Table 3 below. 
Table 3. Conduction of the study

\begin{tabular}{ccccc}
\hline Week No. & Date & Day & Control Group & Experimental Group \\
\hline 1 & $6 / 10$ & Sunday & motivation scale & motivation scale \\
& $9 / 10$ & Wednesday & Conventional method & Activity One (Light Bot) \\
2 & $15 / 10$ & Wednesday & Conventional method & Activity Two (Map Work) \\
3 & $22 / 10$ & Wednesday & Conventional method & Activity Three (OS Maps) \\
& $29 / 10$ & Wednesday & Conventional method & Activity Three (OS Maps) \\
4 & $30 / 10$ & Thursday & motivation scale & motivation scale \\
\hline
\end{tabular}

\subsubsection{The Conventional Method used with the Control Group:}

This method focused mainly on the use of the worksheets conducted from geography past papers (previous tests provided by Cambridge University Press and used as worksheets for students). It used lecturing and question-answer method. Students interacted with geography past papers and with each other, as well as with the instructor. This method was used with the control group.

\subsubsection{The STEAM Approach used with the Experimental Group}

The researchers' perspective of STEAM approach was based on the idea of linking math, physics, technology, and engineering to the learning of geography skills. Math and physics were spotted in the approach as students performed scaled drawings, units' conversion, area calculation, and four directions interpretations. Technology was spotted through the use of materials that enhanced students' learning such as, papers, pencils, rulers, ropes, and calculators. Engineering process took place when students had their own maps designed, produced, tested, and modified. This method was used with the experimental group.

In the LightBot activity conducted for this study, students were asked to give directions (commands) to their little bot to light up all blue tiles. Students learned the s of coding using drag and drop icons on the main screen of the puzzle. The icons were: move forward, turn right, turn left, light up, jump, and repeat (using loops in advanced stages of the game). The stages were ordered based on their difficulty from (s) level, to procedures and then to loops. The player needed to bear in mind how complex a path is, how many blue tiles shall be lit up, how the squares are distributed in the path, and what is the order of icons or commands to be used. In each stage there was a limited number of available space on the screen to place the commands in (for example, (12) empty spaces in $\mathrm{s}$ stage, (20 -28) empty spaces in procedures stage, and (17) empty spaces in the loop stage) which means than students needed to use commands effectively to solve the puzzle. The importance of this activity was pivoted on the fact that learners can benefit from risk-free environment available in this type of games, as well as having more than one correct answer for a certain puzzle. Here the students were observed comparing their solution with each other, trying to validate and compare their codes to see which code was most effective.

In the Map Activity conducted for this study, the students were asked, in groups, to draw a fully scaled map of their classroom, using measuring tools, white sheets of papers and pencils. Students learned many concepts and skills (which are included in geography) related to mathematics, geography, physics and spatial thinking, such as scale drawing, vectors and scalars, units conversion, SI units, the four directions (North, South, East, and West) reference, four-grid reference, measurements of straight and curved distances, and map keys (map legend). While performing this activity, they applied abstraction as they ignored some irrelevant factors to the map such as desk colors, desks heights, and table heights. On the other hand, they focused on relevant factors such as desk width and length, teacher table width and length, distance between desks, distance between door and desks. They utilized the tiles dimensions on the floor to make the measurements of distances easier. Then, they were given printed maps of some part in a city as well as pencils, ropes, rulers, transparent sheets. They were asked to do some measurements, draw paths from a start point to an end. In the OS Map Activity, (on-line website similar to Google Maps), students learned how different maps (including satellite images) of the same region can exist. Such maps are transportation network map, settlement map, greenspace map, cycle network map, Aerial (2-D, and 3-D) map, and leisure map (most detailed map). Abstraction was emphasized in this activity through comparing each type of OS map, finding that some items that were shown in one type were removed in other types based on the purpose of the map.

\subsection{Experimental Manipulations}

This study contained the following types of variables that were under consideration and interest of the researchers:

1) The independent variable was the teaching method; which had two levels; conventional method that was used with the control group, and STEAM approach that was used with the experimental group. 
2) The dependent variable was the motivation towards learning, which was measured using a scale that was developed by the researchers and was given to students before and after treatment and for both groups.

To answer the question of the study, the Statistical Package for the Social Science (SPSS) was used to analyze the data collected and to test the hypothesis set, using descriptive statistics such as:

1) The standard deviation: This was a measure of variability and was used to measure the deviations in the responses of students in control group and experimental group.

2) (MANCOVA): This statistical analysis was used to test whether the differences between the individuals' responses in the tests were statistically significant or not.

3) One way (ANCOVA): This statistical analysis was used to determine the differences on performance due to STEAM approach as a teaching method on the motivation to learning

4) The (partial) Eta square was used to determine the effect size of the independent variable used which is the teaching on the dependent variable.

\subsection{Study Procedures}

The researchers developed the following steps in order to fulfill the study aims:

1) The researchers reviewed relevant literature and previous studies that assisted the preparation of the current study's literature review and procedures.

2) The researchers developed the study instrument.

3) The validity of the instrument was assured by a number of experts in curriculum and instruction, educational technology, and STEM education.

4) The appropriate formal consents were obtained after intentionally choosing the school at which the researchers conducted the study.

5) The two groups of the study (experimental and conventional) were chosen randomly among 10th basic grade students.

6) To verify the reliability of the instrument, the researchers administrated the Motivation towards Learning Scale on a pilot sample from the population of the study but outside the sample.

7) The pre-tests of Motivation towards Learning Scale were conducted upon both groups of study.

8) Students of both groups were trained on the Geography skills by the researchers, who used lecturing and direct teaching with the control group, and STEM approach to the experimental group.

9) The treatment lasted for four weeks during the fall school semester 2019/2020.

10) The post-test of Motivation towards Learning Scale was conducted upon both groups.

11) Students' scores on the instrument (pre and post) were collected and analyzed using SPSS.

12) Results and findings were analyzed and discussed.

\section{Results}

To answer the study question, the means and the standard deviations for the performance of the two study groups, on the total score of the motivation towards learning posttest were calculated. Table 4 below shows the results (the total score is out of 80).

Table 4. Means and standard deviations on the performance of the two study groups on the total score of the motivation pretest and posttest

\begin{tabular}{cccccc}
\hline \multirow{2}{*}{ Group } & \multirow{N}{*}{} & \multicolumn{3}{c}{ Pretest } & \multicolumn{2}{c}{ Posttest } \\
\cline { 3 - 6 } & & Mean & Std. Deviation & Mean & Std. Deviation \\
\hline Experimental & 13 & 59.23 & 6.870 & 56.38 & 5.531 \\
Control & 19 & 57.84 & 7.981 & 58.89 & 7.483 \\
Total & 32 & 58.41 & 7.465 & 57.88 & 6.776 \\
\hline
\end{tabular}

Table 4 indicates an apparent difference between the means for the performance of the two study groups on the total score of the motivation towards learning posttest. The mean of the experimental group who studied using STEAM approach was (56.38), which was lower than the mean of the control group who studied using 
conventional method (58.89). To determine whether the difference between the means of the two study groups was statistically significant at the level of significance $(\alpha=0.05)$, the analysis of covariance (ANCOVA) was used as shown in Table 5 below.

Table 5. The ANCOVA analysis on the performance of the two study groups on the total score for the motivation posttest

\begin{tabular}{ccccccc}
\hline Source & Sum of Squares & df & Mean Square & F & Sig. & Partial Eta Squared \\
\hline Pretest & 587.957 & 1 & 587.957 & 21.668 & .000 & \\
Group & 84.536 & 1 & 84.536 & 3.115 & .088 & .097 \\
Error & 786.909 & 29 & 27.135 & & & \\
Corrected Total & 1423.500 & 31 & & & & \\
\hline
\end{tabular}

Table 5 above shows that the value of (F) related to the teaching method was (3.115), at a level of significance greater than (0.05), which indicates that there was no statistical significant difference between the means of the two study groups according to the teaching method (STEAM approach vs conventional method) on the total score for the motivation towards learning posttest.

Furthermore, the means and the standard deviations on the performance of the two study groups on motivation constructs of interest were calculated in the posttest. Table 6 below shows the results.

Table 6. Means and standard deviations for the performance of the two study groups on all of the motivation constructs of interest in pretest and posttest

\begin{tabular}{lllllll}
\hline \multirow{2}{*}{ Construct } & Group & $\mathrm{N}$ & Pretest & & \multicolumn{2}{c}{ Posttest } \\
\cline { 5 - 7 } & & Mean & Std. Deviation & Mean & Std. Deviation \\
\hline \multirow{3}{*}{ Internal Motivation } & Control & 13 & 11.69 & 3.093 & 11.08 & 2.957 \\
& Total & 19 & 11.32 & 2.029 & 11.47 & 2.170 \\
& Experimental & 13 & 11.77 & 2.475 & 11.31 & 2.481 \\
Grade Motivation & Control & 19 & 11.47 & 2.455 & 11.23 & 1.166 \\
& Total & 32 & 11.59 & 2.342 & 11.16 & 1.608 \\
Class Anxiety & Experimental & 13 & 8.77 & 2.354 & 11.19 & 1.424 \\
& Control & 19 & 8.47 & 2.088 & 7.54 & 1.266 \\
Career Motivation & Total & 32 & 8.59 & 3.098 & 9.21 & 2.149 \\
& Experimental & 13 & 7.15 & 2.698 & 8.53 & 2.000 \\
Self-Efficacy & Control & 19 & 7.11 & 1.625 & 7.00 & 1.732 \\
& Total & 32 & 7.13 & 2.726 & 7.47 & 2.318 \\
Teacher Obedience & Experimental & 13 & 7.46 & 2.311 & 7.28 & 2.083 \\
& Control & 19 & 6.79 & 1.330 & 7.31 & 1.601 \\
& Total & 32 & 7.06 & 1.843 & 6.95 & 1.747 \\
\hline
\end{tabular}

Table 6 indicates an apparent difference between the means on the performance of the two study groups on all motivation constructs of interest in posttest. To determine whether the difference was statistically significant, the multiple analysis of covariance (MANCOVA) was used as shown in Table 7 below. 
Table 7. The MANCOVA analysis on the performance of the two study groups on all of the motivation constructs in the posttest

\begin{tabular}{|c|c|c|c|c|c|c|c|}
\hline Source & Dependent Variable & Sum of Squares & Df & $\begin{array}{c}\text { Mean } \\
\text { Square }\end{array}$ & $\mathrm{F}$ & Sig. & $\begin{array}{c}\text { Partial } \\
\text { Eta Squared }\end{array}$ \\
\hline \multirow{6}{*}{ Group } & internal motivation & 3.413 & 1 & 3.413 & .592 & .449 & .024 \\
\hline & grade motivation & .166 & 1 & .166 & .191 & .666 & .008 \\
\hline & class anxiety & 27.256 & 1 & 27.256 & 9.089 & .006 & .275 \\
\hline & career motivation & 2.212 & 1 & 2.212 & .869 & .361 & .035 \\
\hline & self-efficacy & .008 & 1 & .008 & .006 & .940 & .000 \\
\hline & teacher obedience & .348 & 1 & .348 & .179 & .676 & .007 \\
\hline
\end{tabular}

Table 7 above shows that $(\mathrm{F})$ value in relation to the teaching method was $(0.592)$, at the level of significance $(0.449)$ for the internal motivation construct, $(0.191)$ at the level of significance $(0.666)$ for the grade motivation construct, $(0.869)$ at the level of significance $(0.361)$ for the career motivation construct, $(0.006)$ at the level of significance $(0.940)$ for the self-efficacy construct, and (0.179) at the level of significance $(0.676)$ for the teacher obedience construct. This means that there was no statistical significant difference between the means of both groups of study in those constructs according to teaching method (STEAM approach vs conventional method). In addition, Table 7 shows that $(\mathrm{F})$ value in relation to the teaching method was (9.089) at the level of significance (0.006) for the class anxiety construct. This means that there was statistical significant difference between the means of both groups of study according to the teaching method (STEAM approach vs conventional method) in that construct, and referring to the adjusted means shown in Table 8, it was noticed that the difference in means was in favor of the experimental group in class anxiety construct.

Table 8. Adjusted means and standard deviations on the performance of the two study groups on the class anxiety construct

\begin{tabular}{cccc}
\hline \multirow{3}{*}{ Class Anxiety } & Group & Mean & Std. Error \\
\cline { 2 - 4 } & Experimental & 7.363 & .494 \\
& Control & 9.331 & .405 \\
\hline
\end{tabular}

\section{Discussion}

The results showed that there was no significant effect of using STEAM approach in developing all motivation constructs of interest towards learning except in class anxiety. There was a significant effect in favor of experimental group in class anxiety among 10th grade students. This was due to the fact that STEAM activities, inherently, emphasized on and praised the teamwork that includes time management, communication with peer, peer learning, decision-making and distributing roles based on individual abilities. This agrees with (Bandura, 1994) theory that argued on how peer relations among learners can broaden knowledge of individuals and lower levels of anxiety. Students who were more experienced in a team provided models of effective styles of thinking to others of less experience while functioning in a task. Add on, that great amount of social learning occurs among peers. The fear of not accomplishing a target could generate thoughts of danger and thus increase anxiety levels or, inversely, it may decrease anxiety levels. The increase or decrease in anxiety level is linked to how students cognitively assess their reactions, moreover, as observed during activities and relating to the results on this construct, the anxiety level dropped after treatment in the experimental group, which shows again that group and team work used in STEAM approach can help students better assess their reactions cognitively and as a result lower their anxiety levels. These results also agree with Ji and Kong (2014), who investigated the effect of STEM activity programs on self-efficacy and other motivation constructs among sixth grade students and found significant higher level in self-efficacy of students of experimental group.

Compared to control group, grade motivation, and teacher obedience levels in the experimental group were greater. This might be caused by the less interest in scores observed during assessing the working in STEAM activities compared to assessed work sheets used in conventional method with the control group. The aim of most of STEAM activities was to design and modify required models (building robotic arm) or produce final product (produce city map). The activities were not scored, the assessing method was testing the model or product to find out whether it will work or not. Even in the activity related to coding (Lightbot) the assessing criteria was based on testing the code set by the student and find out whether it will make the robot reach the destination or not. In other 
words, STEAM approach made the interest of gaining marks and the fear of losing marks less among students, who worked in a risk-free environment and were encouraged to test their solutions and use rebuild the product until it would function correctly. Teacher obedience levels seem to be less in the experimental group since teacher role during activities was limited to facilitate and guide students during activities. While in control group, the teacher's role was to give directions and directly instruct students most of the time during the lessons. Despite the fact that careers related to STEAM were introduced and discussed during activities with the experimental group, the career motivation levels found to be lower than those in the control group were. In addition, interest levels in geography as a subject or skills were lower in the experimental group as noticed in the internal motivation scale results. The results disagreed with (Chiang \& Lee 2016) results regarding the effect of teaching using Project Based learning on motivation levels. (Chen \& Howard, 2010) had results that disagreed the other researchers; their findings showed that using the Satellite images while studying science improved students' attitudes towards learning science. The results disagreed with (Han et al., 2014) who used a STEAM education program to increase creativity and motivation levels in science. In addition, the results disagreed with (Al-Kassab, 2011), who aimed at investigating the effect of using different teaching method (reciprocal classroom) on motivation towards learning geography, his results showed improvement in motivation to learn geography among experimental group participants. Low motivation towards learning may be due to the fact that students focus all the time on studying and preparing for their external exams, so they may not be interested in learning geography.

\section{Conclusions}

Among 10th grade students studying geography in Jordan, the study concluded the following:

1) There was a positive significant effect of using STEAM approach on lowering anxiety levels among learners.

2) There was no significant effect of using STEAM approach on developing motivation towards learning in general.

3) There was no significant effect of using STEAM approach on internal motivation, grade motivation, career motivation, self-efficacy, and teacher obedience.

\section{Recommendations}

Based on the findings, this study recommends that there shall be an emphasis on providing teachers with enough and valuable training opportunities on how to activate STEAM approach to ensure meaningful learning for students and to increase their awareness to future careers including STEAM jobs

\section{References}

Al-Kassab, A. (2011). Effect of Reciprocal Teaching Strategy on Primary 10th Grade Students' Geography Achievement and their Motivation to Learning. Dirasat Educational Sciences, 38(5), 1527-1538.

Armstrong, N., Brickman, P., Glynn, S., \& Taasoobshirazi, G. (2011). Science Motivation Questionnaire II: Validation with Science Majors and Nonscience Majors. Journal of Research in Science Teaching, 10(48), 1159-1176. https://doi.org/10.1002/tea.20442

Bandura, A. (1994). Self-efficacy. In V. S. Ramachaudran (Ed.), Encyclopedia of human behavior, 4, 71-81. New York: Academic Press.

Brickman, P., Glynn, S., \& Taasoobshirazi, G. (2009). Science Motivation Questionnaire: Construct Validation With Nonscience Majors. Journal of Research in Science Teaching, 2(46), 127-146. https://doi.org/10.1002/tea.20267

Chen, C., \& Howard, B. (2010). Effect of Live Simulation on Middle School Students' Attitudes and Learning toward Science. Educational Technology \& Society, 13(1), 133-139.

Chiang, C. L., \& Lee, H. (2016). The Effect of Project-Based Learning on Learning Motivation and Problem-Solving Ability of Vocational High School Students. International Journal of Information and Education Technology, 6(9), 709-712. https://doi.org/10.7763/IJIET.2016.V6.779

Gujjar, A., \& Naoreen, B. (2009). Role of Teacher as Classroom Manager. I-Manager's Journal on Educational Psychology, 2(4), 65-73. https://doi.org/10.26634/jpsy.2.4.285

Han, M. J., Hong, S. H., Ko, D. G., \& Kim, D. H. (2014). The Effects of Science Lessons Applying STEAM Education Program on the Creativity and Interest Levels of Elementary Students. Journal of the Korean Association for Science Education, 34(1), 43-54. https://doi.org/10.14697/jkase.2014.34.1.1.00043

International Society for Technology in Education (ISTE). (2016). How Have the ISTE Standards for Students Evolve? Retrieved from https://www.iste.org/standards/for-students 
Ji, I., \& Kong, Y. (2014). The Educational Effect of STEAM Activity Programs on Scientific Attitude, Self-Efficacy, and Motivation for Science Learning. Japan Society for Science Education, 43, 487-488.

Rana, R. A., Mahmood, N., \& Reid, N. (2015). Motivation and Science Performance: Influence on Student Learning in Science. Science Institute (Lahore), 27(2), 1445-1452.

Thomasian, J. (2011). Building a Science, Technology, Engineering, and Math Education Agenda. Washington: National Governors Association. Retrieved from https://files.eric.ed.gov/fulltext/ED532528.pdf

\section{Appendix A}

\section{The Study Instrument: Motivation towards Learning Scale}

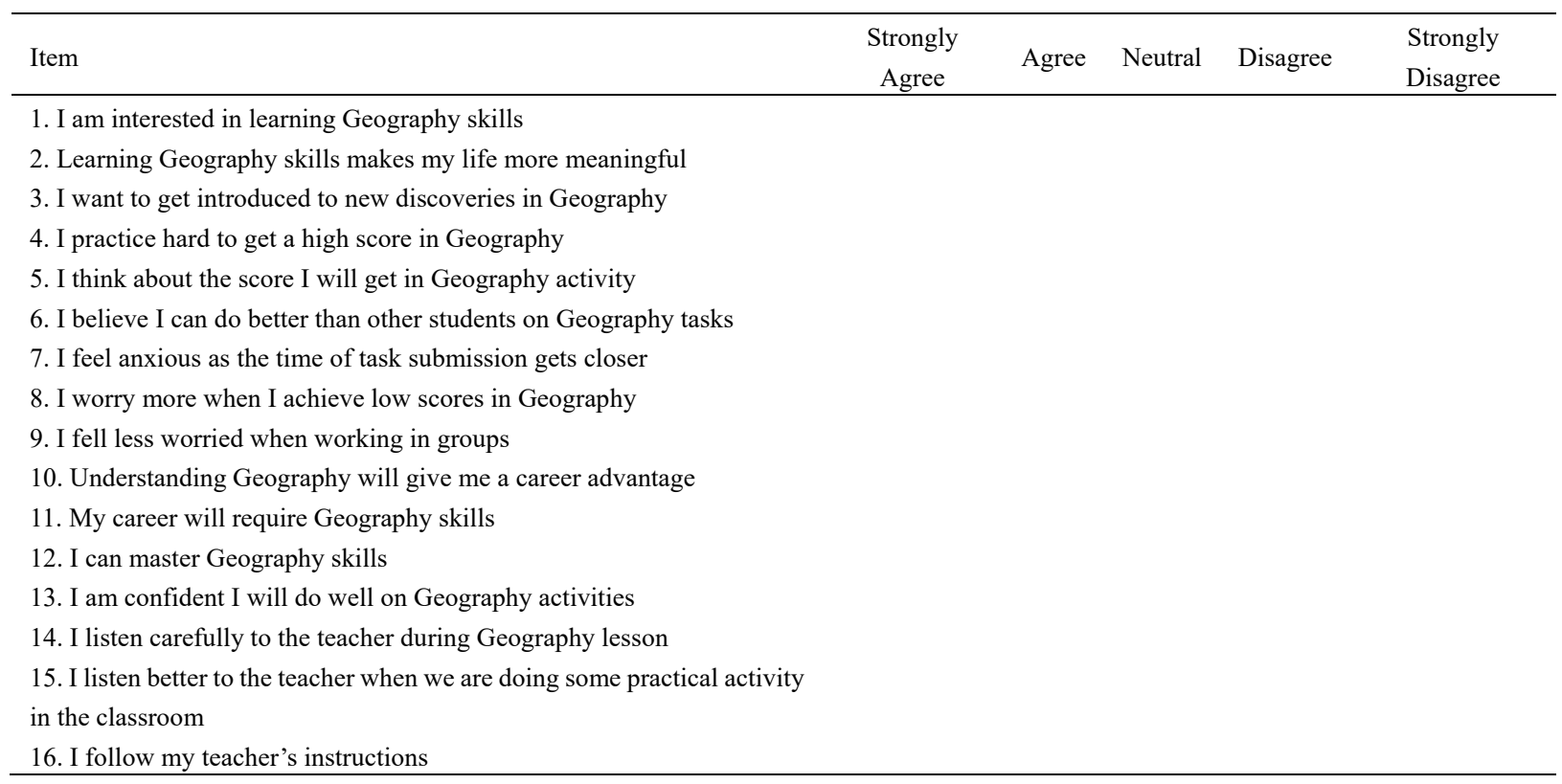

\section{Copyrights}

Copyright for this article is retained by the author(s), with first publication rights granted to the journal.

This is an open-access article distributed under the terms and conditions of the Creative Commons Attribution license (http://creativecommons.org/licenses/by/4.0/). 